\title{
Synthesis of ZnO nanostructures by microwave irradiation for energy conversion material in for dye sensitized solar cells and materials for photocatalytic dye degradation applications
}

\author{
Surangkana WANNAPOP ${ }^{1, \dagger}$, Asanee SOMDEE ${ }^{1}$, Titipun THONGTEM ${ }^{2,3}$ and Somchai THONGTEM ${ }^{4}$ \\ ${ }^{1}$ Faculty of Science, Energy and Environment, King Mongkut's University of Technology North Bangkok, \\ Rayong Campus, Rayong 21120, Thailand \\ ${ }^{2}$ Department of Chemistry, Faculty of Science, Chiang Mai University, Chiang Mai 50200, Thailand \\ ${ }^{3}$ Center of Excellence in Materials Science and Technology, Chiang Mai University, Chiang Mai 50200, Thailand \\ ${ }^{4}$ Department of Physies and Materials Science, Faculty of Science, Chiang Mai University, Chiang Mai 50200, Thailand
}

\begin{abstract}
ZnO nanoplates and ZnO nanostructure flowers were successfully synthesized in alkaline solutions containing different contents of sodium hydroxide by a cyclic-microwave method. The as-synthesized products were characterized by X-ray Diffraction, Field Emission Scanning Electron Microscopy and ultraviolet (UV)-visible spectroscopy. The crystal structure of $\mathrm{ZnO}$ nanoplates and nanostructure flowers are wurtzite structure with energy band gap of 3.201-3.217 eV. In this research, these products were applied as energy harvesting materials in dye sensitized solar cells (DSSCs) and also used photocatalytic degradation of methylene blue (MB) under UV irradiation. In the case of photo conversion materials, the DSSCs based ZnO nanoplates showed the best performance of photoconversion to electricity at 1.5 AM illumination. Moreover, it also well performed at dye degradation of MB under UV irradiation.

(O2019 The Ceramic Society of Japan. All rights reserved.
\end{abstract}

Key-words : ZnO nanoplates, ZnO nanostructure flowers, Energy gap, Dye sensitized solar cells, Photocatalytic

[Received January 8, 2019; Accepted April 3, 2019]

\section{Introduction}

Energy shortages and environmental pollution have been investigated in the past two decades. Overcoming shortages of energy and environment problems, there are many works devoted to solve the problems. Since, the solar energy is an alternative energy that can be accessible and easy to utilize. Solar Cell is a general device which can be able to convert the light to the electricity. Nowadays, there are various types of solar cells used in the present day. Dye sensitized solar cells (DSSCs) are promising devices used for photovoltaic conversion due to a low production cost and good conversion efficiency which are maintained under weak indoor light. ${ }^{1,2)}$

Moreover, due to the growing economy of the world today has caused various environmental pollution problems. For example, the dye business is currently being developed to improve the quality of dye, e.g. to have beautiful colors, and more resistant to various conditions. Therefore, the dye contamination to the water is inevitable. ${ }^{3)}$ There are physical and chemical methods to treat these contaminants.

The use of solar power and semiconductor in the

Corresponding author: S. Wannapop; E-mail: surangkana. w@sciee.kmutnb.ac.th photocatalytic process, which is widely popular in the removal of organic contaminants. 33,4$)$

Zinc oxide $(\mathrm{ZnO})$ is a wide band gap $(3.37 \mathrm{eV})$ semiconductor and can be used in many applications, such as photocatalytic, antibacteria, gas sensors, photodetectors and DSSCs. ${ }^{3)-8)} \mathrm{A}$ wide varieties of $\mathrm{ZnO}$ nanoparticles are depended on the morphological properties and their preparation methods. Various nanostructures of $\mathrm{ZnO}$ have been used in fabrication of DSSCs and photocatalysts: nanoparticles, nanospheres, hexagonal disks, hexagonal bilayer disk-like structures, 3D flower-like hierarchitectures, nanowires, nanosheets, tetrapod and nanorods. ${ }^{9-21)}$ However, the effect of $\mathrm{NaOH}$ content to the morphology of $\mathrm{ZnO}$ to be used as energy harvesting and photocatalytic materials is rarely investigated.

In the present work, $\mathrm{ZnO}$ nanoplates and $\mathrm{ZnO}$ nanostructure flowers were synthesized in solutions containing different concentrations of $\mathrm{NaOH}$ by a cyclic-microwave radiation. Effects of the as-synthesized $\mathrm{ZnO}$ with different morphologies with respect to the properties, DSSC and photocatalytic application were discussed in this work.

\section{Materials and methods}

\subsection{Preparation of $\mathrm{ZnO}$ samples}

Zinc acetate dihydrate $(5.0 \mathrm{mmol})$ and different content of sodium hydroxide $(\mathrm{NaOH})$ were separately dissolved in 
Table 1. $\mathrm{ZnO}$ products of the present research

\begin{tabular}{ccc}
\hline ZnO products & $\mathrm{Zn}\left(\mathrm{CH}_{3} \mathrm{COO}\right)_{2} \cdot 2 \mathrm{H}_{2} \mathrm{O}(\mathrm{mmol})$ & $\mathrm{NaOH}(\mathrm{mmol})$ \\
\hline $\mathrm{S} 1$ & 5 & none \\
$\mathrm{S} 2$ & 5 & 15 \\
$\mathrm{~S} 3$ & 5 & 30 \\
$\mathrm{~S} 4$ & 5 & 45 \\
$\mathrm{~S} 5$ & 5 & 60 \\
$\mathrm{~S} 6$ & 5 & 75 \\
\hline
\end{tabular}

Table 2. Photoanodes of the present research

\begin{tabular}{ccccc}
\hline Photoanodes & ZnO $(\mathrm{g})$ & PEG $(\mathrm{g})$ & Ethanol $95 \%(\mathrm{ml})$ & Distilled water $(\mathrm{ml})$ \\
\hline S2G1 & 0.35 & 0.15 & 0.5 & 0.5 \\
S3G1 & 0.35 & 0.15 & 0.5 & 0.5 \\
S4G1 & 0.35 & 0.15 & 0.5 & 0.5 \\
S5G1 & 0.35 & 0.15 & 0.5 & 0.5 \\
S6G1 & 0.35 & 0.15 & 0.5 & 0.5 \\
\hline
\end{tabular}

$25 \mathrm{ml}$ of distilled water. They were mixed together and vigorously stirred for $30 \mathrm{~min}$. Details of the products were summarized in Table 1. The reaction was cyclically proceeded by $450 \mathrm{~W}$ microwave with $5 \mathrm{~min}$ on for every $1 \mathrm{~min}$ interval for 5 cycles to produce $\mathrm{ZnO}$ nanoplates and nanostructure flowers. In the end, the system was left to naturally cool down to room temperature. The products were washed with deionized water and $95 \%$ ethanol, and dried at $80^{\circ} \mathrm{C}$ for $24 \mathrm{~h}$.

\subsection{Fabrication of $\mathrm{ZnO}$ photoanodes of DSSC}

The as-obtained precursor powder was ground in an agate mortar to homogenize $\mathrm{ZnO}$. Sol-gel solutions were prepared by dissolving $\mathrm{ZnO}$ and PEG (MW $=20,000$ $\mathrm{g} / \mathrm{mol}$ ) in ethanol mixed distilled water and followed by stirring at room temperature for $1.5 \mathrm{~h}$ (Table 2). To make films, the paste was applied onto a conducting substrate [fluorine-doped tin oxide (FTO)-coated glass, $14 \Omega$ /square, Aldrich] by doctor blading using adhesive scotch tape as a frame $\left(0.5 \times 0.5 \mathrm{~cm}^{2}\right)$ and spacer. The tape was pulled out, the films were left to dry at $80^{\circ} \mathrm{C}$ for $30 \mathrm{~min}$, and asprepared photoanodes were calcined at $450^{\circ} \mathrm{C}$ for $1.5 \mathrm{~h}$.

\subsection{DSSC fabrication and performance measurement}

The $\mathrm{ZnO}$ film as a DSSC working electrode was immersed in $0.5 \mathrm{mM}$ solution containing N719 dye (Ditetrabutylammonium cis-bis(isothiocyanato) bis(2,2'-bipyridyl-4,4'-dicarboxylato) ruthenium(II), Sigma-Aldrich) in ethanol for $1 \mathrm{~h}$. To prepare the counter electrode, the platinum $(\mathrm{Pt}$ ) catalyst (Platisol $\mathrm{T}$, Solarlonix) was coated on a FTO-coated glass by blade coating technique and annealed at $450^{\circ} \mathrm{C}$ for $30 \mathrm{~min}$. The dye-covered $\mathrm{ZnO}$ electrode and Pt-counter electrode were assembled as sandwich type cell and sealed with a suitable $\sim 25 \mu \mathrm{m}$ thick Surlyn hot-melt gasket. An Iodolyte AN-50 (Solaronix) electrolyte was injected in between the counter and working electrodes and pinched together for solar cell performance testing.
Photocurrent-voltage characteristics were measured by a computer controlled system under a simulated solar radiation of $100 \mathrm{~mW} / \mathrm{cm}^{2}$. The performance parameters such as short-circuit current density $\left(J_{\mathrm{SC}}\right)$, open-circuit voltage $\left(V_{\mathrm{OC}}\right)$, fill factor $(\mathrm{FF})$ and photonic conversion efficiency $(\eta)$ were determined. Electronic and ionic processes of the DSSCs were tested by an electrochemical impedance spectroscopy (EIS) at a frequency ranging from $1 \mathrm{~Hz}$ to $100 \mathrm{kHz}$.

\subsection{Dye-degradation of methylene blue (MB) in ultraviolet (UV) irradiation}

The photocatalytic activity of all $\mathrm{ZnO}$ were evaluated with a photoreaction system. Typically, the $0.2 \mathrm{~g}$ of each $\mathrm{ZnO}$ photocatalyst was added to $250 \mathrm{~mL}$ of aqueous solution containing MB dye with a concentration of $5 \mathrm{mg} / \mathrm{L}$. Note that the mixed solution was kept in dark for $30 \mathrm{~min}$ for the equilibrium of dye adsorption and desorption on the $\mathrm{ZnO}$ surface before irradiation. Then, the suspension was exposed to the black light blue (BLB) with wavelength of $375 \mathrm{~nm}$. The reaction solution was stirred. Each sample was taken out at an hour interval.

\subsection{Characterization}

The products were characterized by an X-ray diffraction (XRD) (Rigaku Miniflex II) equipped with a graphite monochromator of $\mathrm{Cu}-\mathrm{K} \alpha$ radiation $(\lambda=0.1542 \mathrm{~nm})$ at a scanning rate of $0.02^{\circ} / \mathrm{s}$ over the $2 \theta$ range of $10-80^{\circ}$. The presence of $\mathrm{ZnO}$ was certified by field emission scanning electron microscopy (FE-SEM, JEOL JSM-6335F) operating at $15.0 \mathrm{kV}$ beam energy. Spectroscopy absorbance was carried out by a UV-visible spectrometer (SHIMADZU UV 2006).

\section{Results and discussion}

\subsection{Phase and morphology}

In this research, no $\mathrm{ZnO}$ was synthesized in the $\mathrm{NaOH}-$ free solution. In Fig. 1, XRD patterns of $\mathrm{ZnO}$ synthesized in the solutions containing different contents of $\mathrm{NaOH}$ by cyclic-microwave radiation show peaks at $2 \theta$ of 31.683 , $34.432,36.268,47.533,56.687,62.827,66.344,67.756$ and $69.059^{\circ}$ which were respectively indexed to the (100), (002), (101), (102), (110), (103), (200), (112) and (201) planes of wurtzite $\mathrm{ZnO}$ (JCPDS card no.01-080-0075). ${ }^{22)}$ Clearly, the major diffraction peaks of $\mathrm{ZnO}$ are at the same position, except for the peak height. The (100) and (200) peaks were almost at the same intensities for the $\mathrm{ZnO}$ nanoplates (Fig. 2) synthesized in the solutions containing 15 and $30 \mathrm{mmol} \mathrm{NaOH}$. Further increasing the content of $\mathrm{NaOH}$ to 45,60 and $75 \mathrm{mmol}$, the $\mathrm{ZnO}$ nanoplates were transformed into $\mathrm{ZnO}$ nanostructure flowers (Fig. 2) and the intensity of the (100) peak was strengthened in sequence.

SEM images of $\mathrm{ZnO}$ nanoplates and nanostructure flowers are shown in Fig. 2. In the solutions containing 15 and $30 \mathrm{mmol} \mathrm{NaOH}$ (S2G1 and S3G1), the products were composed of a number of nanoplates orientated in different directions. The plates became larger when more 


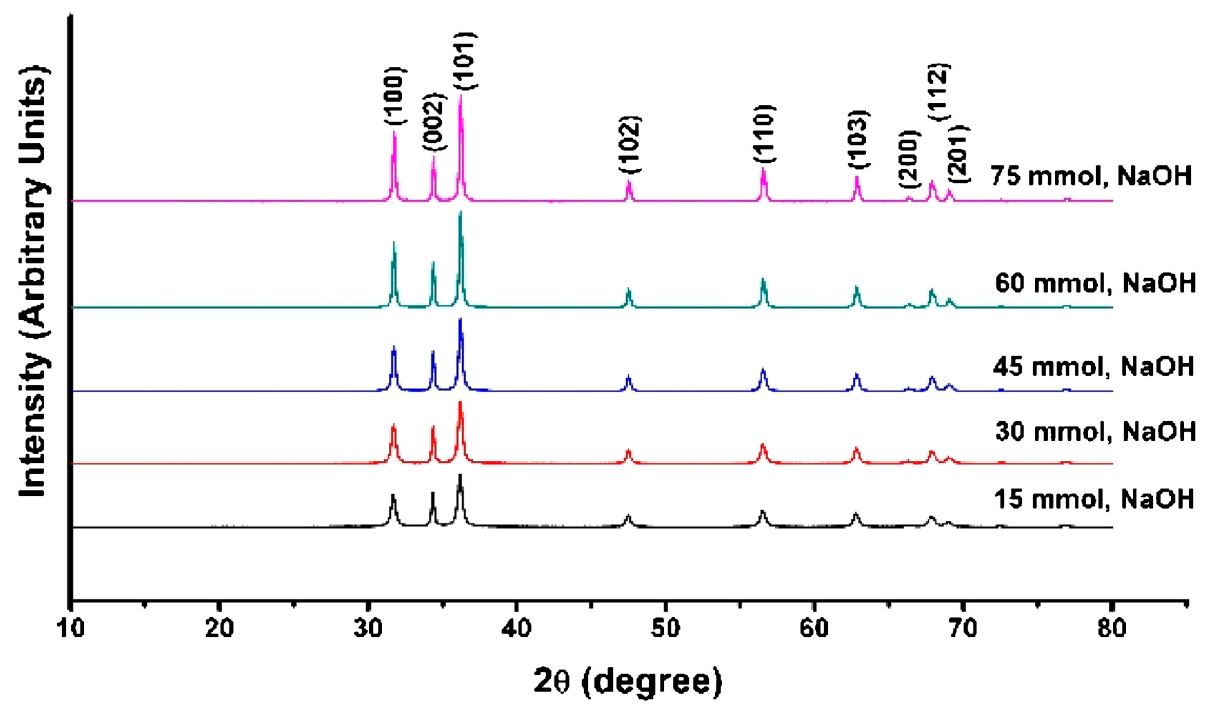

Fig. 1. XRD patterns of $\mathrm{ZnO}$ samples synthesized in the solutions containing different contents of $\mathrm{NaOH}$.

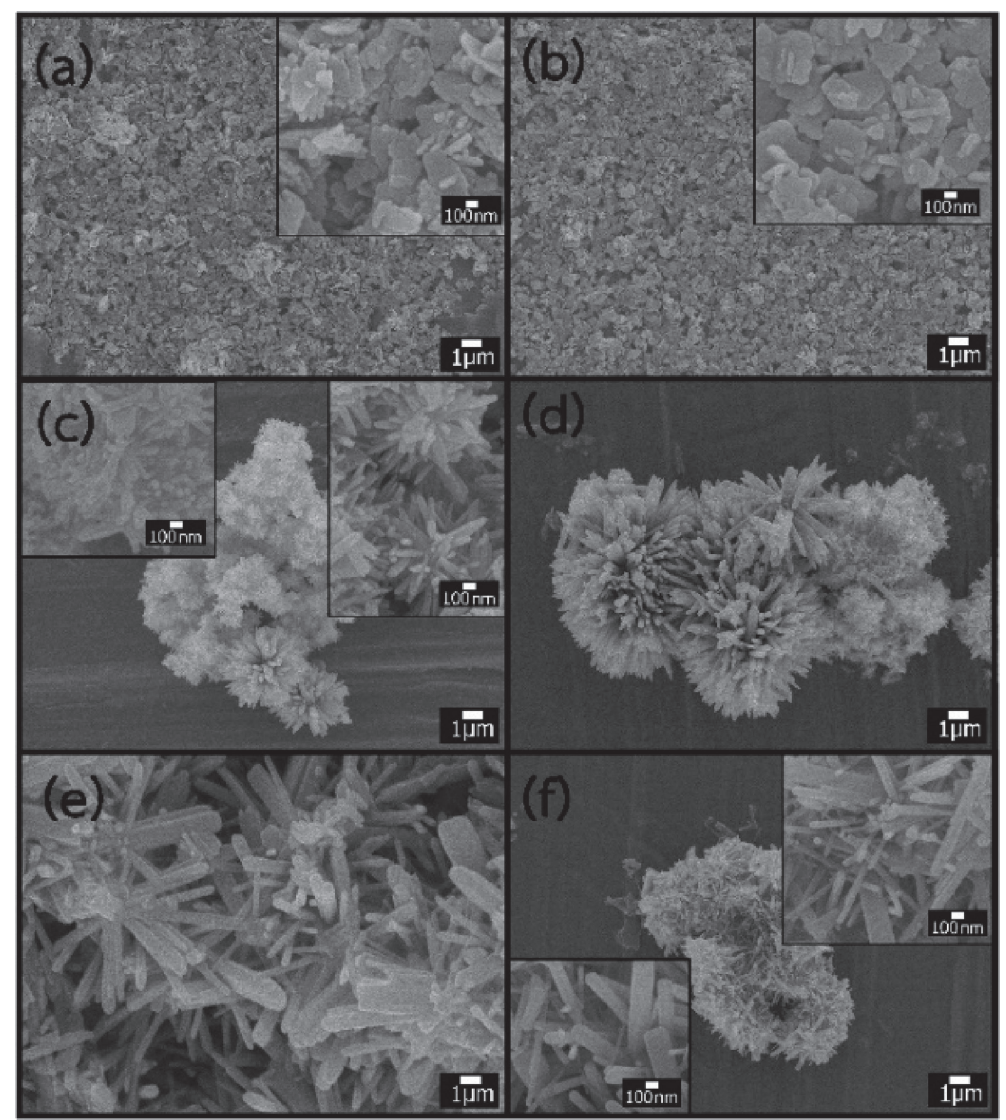

Fig. 2. SEM images of (a, b) ZnO nanoplates of S2G1 and S3G1 and ZnO nanostructure flowers of (c) S4G1, (d-e) S5G1 and (f) S6G1.

$\mathrm{NaOH}$ was used, the plates $(30 \mathrm{mmol} \mathrm{NaOH})>$ the plates $(15 \mathrm{mmol} \mathrm{NaOH})$. When 45, 60 and $75 \mathrm{mmol} \mathrm{NaOH}$ were used (S4G1, S5G1 and S6G1), the products were composed of a number of nanorod petals composing the flowerlike clusters. The flowers were larger when more $\mathrm{NaOH}$ was added.

Top view and side view (cross section) of different $\mathrm{ZnO}$ films are shown in Fig. 3. The nanoplates and the nanostructure flowers still retained much of their original morphologies after coating on FTO by Doctor-blade method. It is to be noted that the film thickness of all the samples (S2G1-S6G1) after calcined at $450^{\circ} \mathrm{C}$ for $1.5 \mathrm{~h}$ are typically of $10.0-15.0 \mu \mathrm{m}$ height.

\subsection{Energy gap}

The energy band gap was calculated by assuming that $\mathrm{ZnO}$ has a direct type of transition by using the following equation 


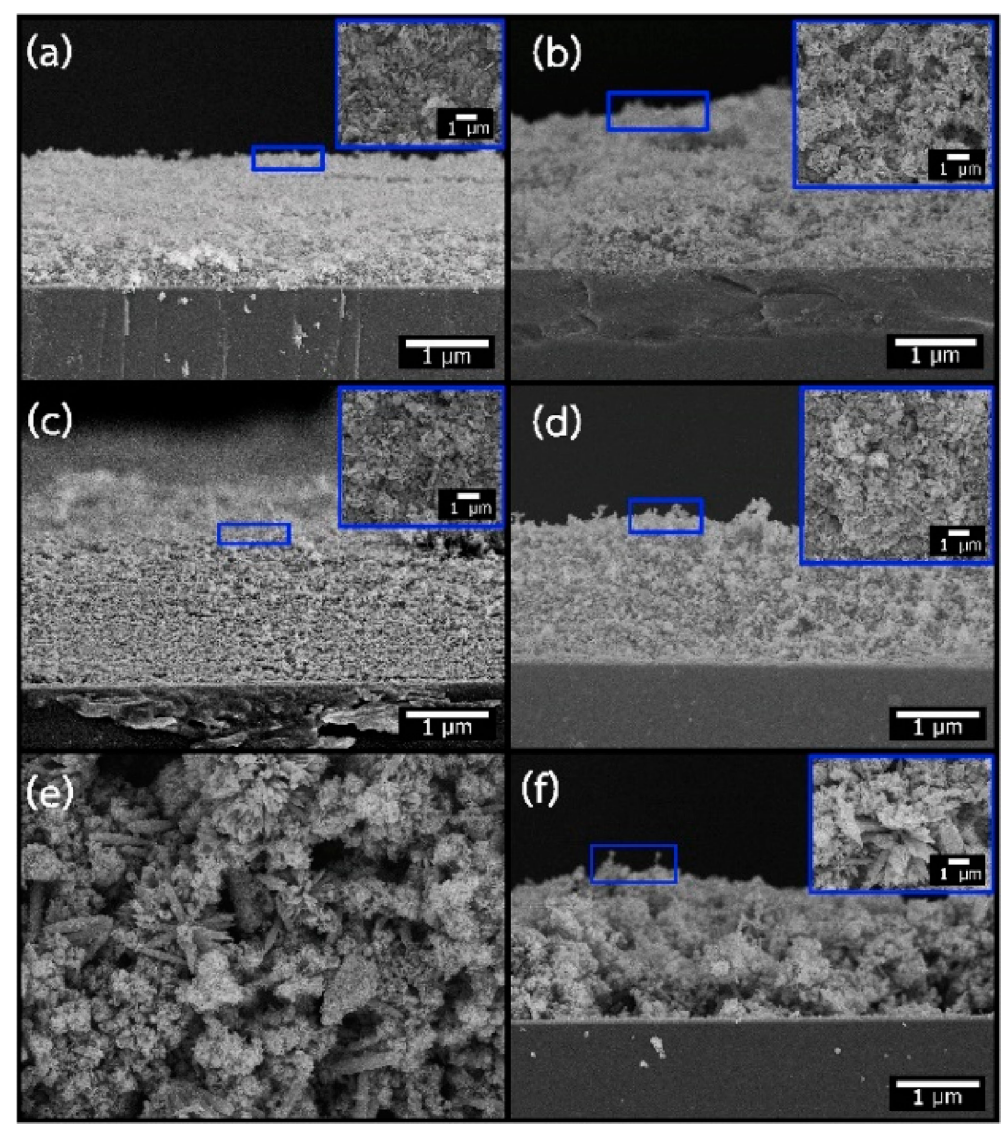

Fig. 3. SEM images of (a, b) S2G1, (c, d) S3G1, (e) S4G1 and (f) S5G1. (a), (c), and (e) are top view, and (b), (d) and (f) are side view (cross section).

$$
(\alpha h \nu)=A\left(h \nu-E_{\mathrm{g}}\right)^{n}
$$

where $\alpha, h v, A, E_{\mathrm{g}}$ and $n$ are the absorption coefficient, photonic energy, proportionality constant, energy gap and a constant, respectively. The $n$ pure number decides the type of transition. ${ }^{7)}$ The energy band gaps of S2G1, S3G1, S4G1, S5G1 and S6G1 [Fig. 4(a)] were evaluated to be 3.201-3.217 eV.

To estimate the dye-loading capacity, each specimen was immersed separately into a $0.5 \mathrm{M} \mathrm{NaOH}$ solution, and afterwards the solution of desorbed dye were evaluated using the UV-visible spectrometer where the absorption spectra of samples were showed in Fig. 4(b). In overall, the adsorption height of dye-desorption were similar which signifies that the occupied dye molecule on the surface are approximately the same in all sample.

\subsection{DSSC performance}

The effects of different morphologies of $\mathrm{ZnO}$ addition to the DSSCs on the electrical properties have been investigated. The DSSCs based on $\mathrm{ZnO}$ were fabricated and their electrical properties were compared. Photocurrentvoltage characteristic of the DSSCs were measured, where the DSSC performance was calculated by the following equations

$$
\text { Fill Factor : }(F F)=\frac{J_{\max } \cdot V_{\max }}{J_{\mathrm{SC}} \cdot V_{\mathrm{OC}}}
$$

$$
\text { Efficiency : } \eta(\%)=\frac{J_{\mathrm{SC}} \cdot V_{\mathrm{OC}} \cdot F F}{P_{\mathrm{in}}} \times 100
$$

where $J_{\max }$ and $V_{\max }$ is the current density and voltage at the maximum power $(\mathrm{W}), J_{\mathrm{SC}}$ is the short-circuit current density, $V_{\mathrm{OC}}$ is the open-circuit voltage and $P_{\text {in }}$ is the incident power. All measured parameters of the DSSCs are summarized in Table 3.

In Fig. 5(a), the open-circuit photovoltage $\left(V_{\mathrm{OC}}\right)$ is almost at the same value which are typically $0.52-0.56 \mathrm{~V}$. Results showed noticeable that the current density of each sample are different. The $J_{\mathrm{SC}}$ of S2G1 and S3G1 ZnO nanoplates were greater than others. Therefore, it is conceivable that the morphology of $\mathrm{ZnO}$ photoanode influenced to the photocurrent. Hence, the greater photocurrent affects to the higher efficiency of DSSCs in this work. The EIS can be further investigated the impedance of DSSCs films.

The analysis of EIS was used to study electron diffusion and the photonic-electric conversion efficiency of DSSCs. The EIS measurement is used to determine the impedance of DSSCs at a frequency range of $0.1 \mathrm{~Hz}$ to $100 \mathrm{kHz}$ under one-sun illumination where potential of each measurement was set equal to $10 \mathrm{mV}^{23), 24)}$ The Nyquist plots and the EIS model are represented in Fig. 5(b). The Nyquist plots shows a small semicircle represents the resistance of the redox charge transfer at the counter electrode and the large semicircle refers to the electron transfer resistance at 


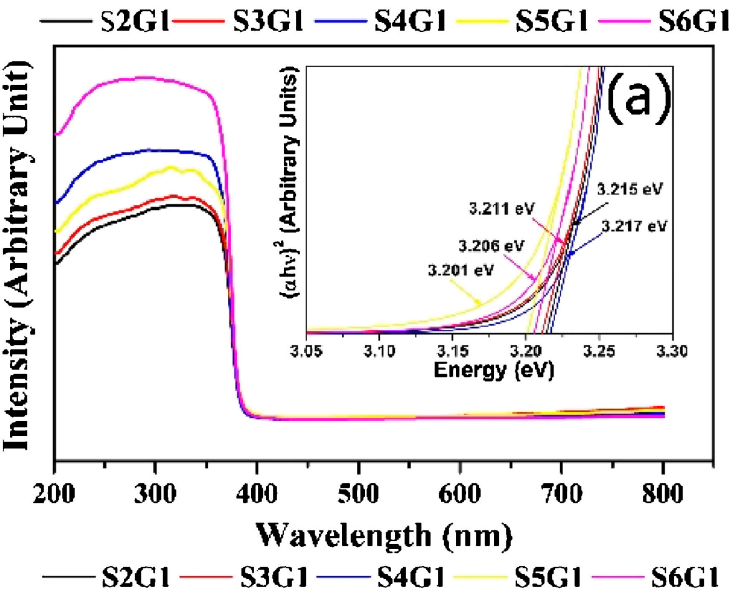

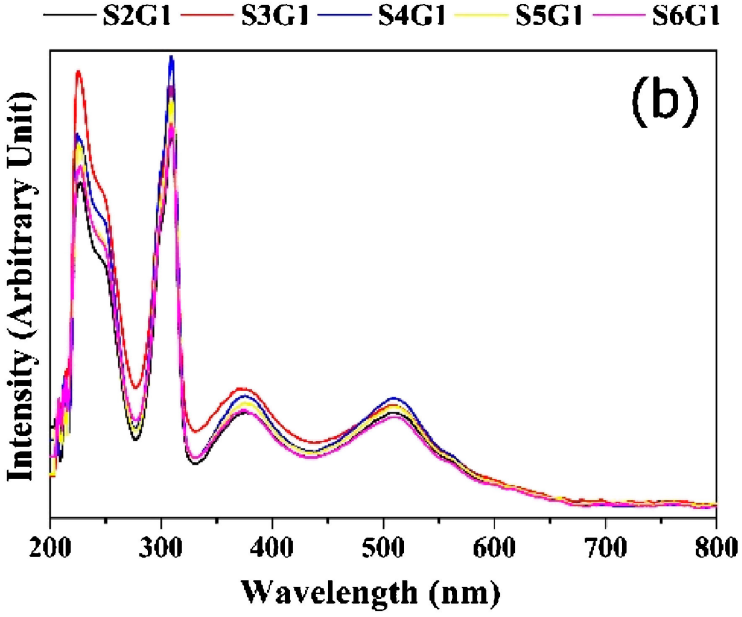

Fig. 4. (a) The plot of $(\alpha h v)^{2}$ versus photon energy (hv) for estimation of the direct energy gap of the $\mathrm{ZnO}$ films and (b) UVvis spectra of desorbed dye solution from DSSCs photoanode.

Table 3. Photovoltaic performance of the DSSCs fabricated from $\mathrm{ZnO}$ nanoplates and $\mathrm{ZnO}$ nanostructure flowers

\begin{tabular}{ccccc}
\hline Samples & $J_{\mathrm{SC}}\left(\mathrm{mA} / \mathrm{cm}^{2}\right)$ & $V_{\mathrm{OC}}(\mathrm{V})$ & $F F$ & $\eta(\%)$ \\
\hline S2G1 & 9.55 & 0.52 & 0.61 & 3.08 \\
S3G1 & 9.38 & 0.56 & 0.63 & 3.36 \\
S4G1 & 3.88 & 0.56 & 0.56 & 1.22 \\
S5G1 & 6.23 & 0.56 & 0.61 & 2.13 \\
S6G1 & 5.68 & 0.54 & 0.62 & 1.91 \\
\hline
\end{tabular}

the $\mathrm{ZnO} /$ dye/electrolyte interface. The resistance of $\mathrm{ZnO} /$ dye/electrolyte interface were fitted as $R_{\mathrm{CT}}$ and $R_{\mathrm{W}}$, whereas $R_{\mathrm{S}}$ represents the sheet resistance of FTO and the contact resistance between FTO and $\mathrm{ZnO}$ film.

Figure 5(c) shows the Bode phase plot of EIS spectra display the frequency peaks of the charge transfer at different interface of the DSSCs. The dominant peak frequency at meddle frequency $(\sim 100 \mathrm{~Hz})$ shows the electron transfer process occurred at the $\mathrm{ZnO} /$ dye/electrolyte interface. The electron lifetime of the DSSCs is calculated by the following equation. ${ }^{25)}$

$$
\tau=\frac{1}{2 \pi f_{\max }}
$$

where $f_{\max }$ is the peak frequency of a semicircle at the middle frequency region.
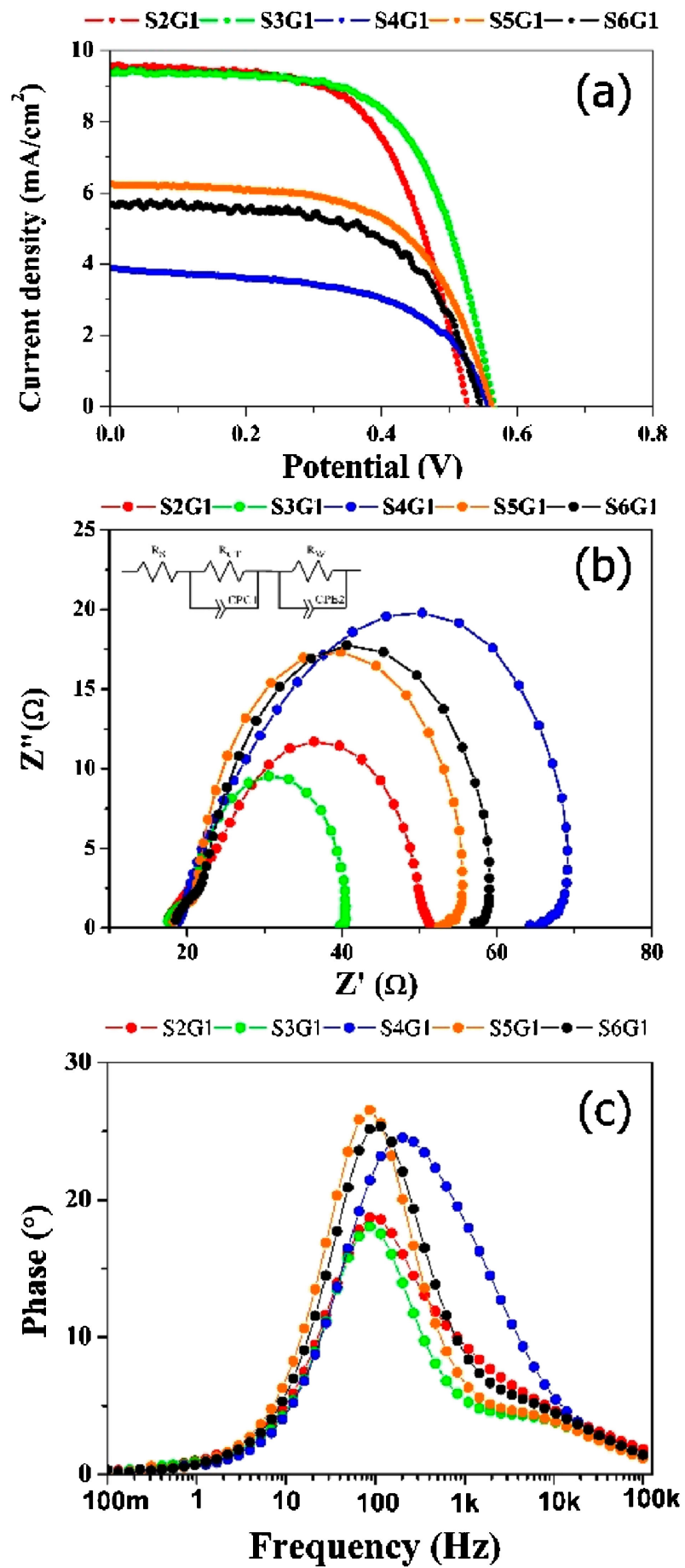

Fig. 5. (a) Current density vs. Voltage curves of DSSCs, (b) Nyquist plot and (c) Bode phase plot under one-sun illumination of DSSCs.

In Table 4, all fitted parameters between the experiment data and the EIS model, including calculated electron lifetime are listed in Table 4 . The $R_{\mathrm{S}}$ of all components of the fabricated DSSCs were in the range of 17.0-18.8 $\Omega$, while the $R_{\mathrm{CT}}$ and $R_{\mathrm{W}}$ of each sample were different. The electron lifetime of all DSSCs based on different $\mathrm{ZnO}$ nanostructure were typically $0.77-1.90 \mathrm{~s}$. As a results, the total amount resistance of $R_{\mathrm{CT}}$ and $R_{\mathrm{W}}$ are almost a critical role for DSSCs performance. Since, the overall resistance 
of DSSCs indicated their performances, the S3G1 sample are the highest performance, following by the S2G1.

In this research, the variation of $\mathrm{NaOH}$ used as precursor for $\mathrm{ZnO}$ nanostructure synthesis using the microwave method for DSSCs photoanode fabrication yielded two nanostructures, the nanoplate and the nanostructure flowers. The results showed that the DSSCs based on $\mathrm{ZnO}$ nanoplate photoanode has better performance than the DSSCs based on $\mathrm{ZnO}$ nanostructure flowers.

\subsection{Photocatalytic performance}

Figure 6 showed the photocatalyst activities under BLB irradiation of the $\mathrm{ZnO}$ photocatalysts prepared at different

Table 4. $R_{\mathrm{S}}, R_{\mathrm{CT}}, R_{\mathrm{W}}$ and $\tau$ of the DSSCs based on $\mathrm{ZnO}$ nanoplates and $\mathrm{ZnO}$ nanostructure flowers

\begin{tabular}{ccccc}
\hline Samples & $R_{\mathrm{S}}(\Omega)$ & $R_{\mathrm{CT}}(\Omega)$ & $R_{\mathrm{W}}(\Omega)$ & $\tau(\mathrm{ms})$ \\
\hline S2G1 & 17.0 & 11.8 & 21.6 & 1.65 \\
S3G1 & 17.3 & 3.84 & 19.5 & 1.85 \\
S4G1 & 18.8 & 27.3 & 25.7 & 0.77 \\
S5G1 & 18.0 & 3.52 & 34.6 & 1.90 \\
S6G1 & 18.2 & 4.60 & 37.3 & 1.50 \\
\hline
\end{tabular}
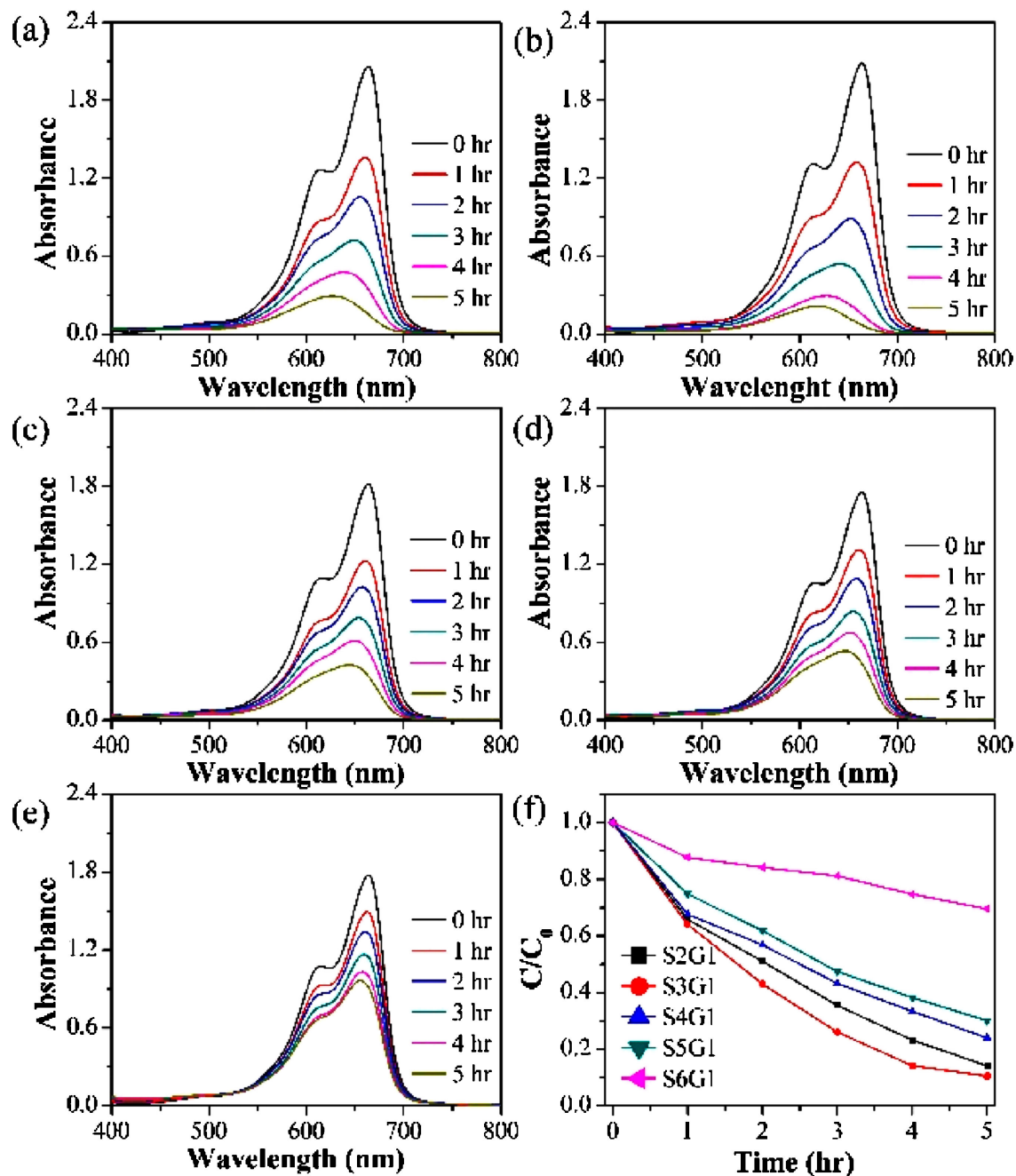

Fig. 6. Degradation curve of MB in the presence of ZnO (a) S2G1, (b) S3G1, (c) S4G1, (e) S5G1, (d) S6G1 and reaction rate ratio $\left(C / C_{0}\right)$ versus irradiation time of $\mathrm{UV}$ with different $\mathrm{ZnO}$. 
as-obtained $\mathrm{ZnO}$ products were hexagonal wurtzite structure of nanoplates and nanostructure flowers. The optimized $\mathrm{ZnO}$ nanoplates and $\mathrm{ZnO}$ nanostructure flowers were used as photoanodes to fabricate the DSSCs. The EIS results revealed that the DSSC based on $\mathrm{ZnO}$ nanostructure flowers and nanoplate had similar electron lifetime. However, the DSSC based on $\mathrm{ZnO}$ nanoplate had lower impedance of charge diffusion at $\mathrm{ZnO} /$ dye/electrolyte interface than the DSSC based on $\mathrm{ZnO}$ nanostructure flower. Among them, the S3G1 $\mathrm{ZnO}$ nanoplates based photoanode DSSC exhibited the best photovoltaic conversion efficiency of $3.36 \%$. Moreover, the S3G1 $\mathrm{ZnO}$ nanoplates has also a good photocatalytic activity which can be degraded MB by $90 \%$.

Acknowledgements This research was funded by King Mongkut's University of Technology North Bangkok. Contract no. KMUTNB-60-GOV-066.

\section{References}

1) T. Marimuthu, N. Anandhan and R. Thangamuthu, Appl. Surf. Sci., 428, 385-394 (2018).

2) Y. Kusumawati, J. Massin, C. Olivier, T. Toupance, A. L. Ivansyah, M. A. Martoprawiroc, B. Prijamboedi, C. L. Radiman and T. Pauporté, J. Photoch. Photobio. A, 341, 69-77 (2017).

3) H. J. Jung, R. Koutavarapu, S. Lee, J. H. Kim, H. C. Choi and M. Y. Choi, J. Environ. Sci., 74, 107-115 (2018).

4) C. Jaramillo-Páez, P. Sánchez-Cid, J. A. Navío and M. C. Hidalgo, J. Env. Chem. Eng., 6, 7161-7171 (2018).

5) K. Qi, B. Cheng, J. Yu and W. Ho, J. Alloy. Compd., 727, 792-820 (2017).

6) Y. Zhang, Y. Liu, L. Zhou, D. Liu, F. Liu, F. Liu, X. Liang, X. Yan, Y. Gao and G. Lu, Sensor. Actuat. B-Chem., 273, 991-998 (2018).

7) T. Yang, B. Sun, L. Ni, X. Wei, T. Guo, Z. Shi, F. Han and L. Duan, Curr. Appl. Phys., 18, 859-863 (2018).

8) A. Hezam, K. Namratha, Q. A. Drmoshc, B. N. Chandrashekar, G. K. Jayaprakash, C. Cheng, S. S.
Swamy and K. Byrappa, Ceram. Int., 44, 7202-7208 (2018).

9) B. L. Martínez-Vargas, M. Cruz-Ramírez, J. A. DíazReal, J. L. Rodríguez-López, F. J. Bacame-Valenzuela, R. Ortega-Borges, Y. Reyes-Vidal and L. Ortiz-Frade, J. Photoch. Photobio. A, 369, 85-96 (2019).

10) A. M. Golsheikh, K. Z. Kamali, N. M. Huang and A. K. Zak, Powder Technol., 329, 282-287 (2018).

11) Y. Mao, Y. Li, Y. Zou, X. Shen, L. Zhu and G. Liao, Ceram. Int., 45, 1724-1729 (2019).

12) M. Saleem, M. A. Ahmad, L. Fang, R. Raza, M. N. Akhtar and S. U. Rehman, Mater. Res. Bull., 96, 211217 (2017).

13) C. M. Chou, Y. C. Chang, P. S. Lin and F. K. Liu, Mater. Chem. Phys., 201, 18-25 (2017).

14) J. He, W. Wang, X. Zheng, Y. Cao, L. Kong, Y. Wu, Z. Wu and J. Kang, Physica E, 103, 430-434 (2018).

15) H. Guo, R. Ding, N. Li, K. Hong, L. Liu and H. Zhang, Physica E, 105, 156-161 (2019).

16) Y. X. Wang, Z. C. Shen, D. D. Huang and Z. S. Yang, Mater. Lett., 214, 88-90 (2018).

17) J. Li, Z. Zhang, J. Lang, J. Wang, Q. Zhang, J. Wang, Q. Han and J. Yang, J. Lumin., 204, 573-580 (2018).

18) X. Fenglin, Optik, 127, 3078-3081 (2016).

19) S. Çakar and M. Özacar, Sol. Energy, 155, 233-245 (2017).

20) S. Tian, Q. Liu, J. Sun, M. Zhu, S. Wu and X. Zhao, J. Colloid Interf. Sci., 534, 389-398 (2019).

21) A. F. Vale da Fonseca, R. L. Siqueira, R. Landers, J. L. Ferrari, N. L. Marana, J. R. Sambrano, F. de Almeida La Porta and M. A. Schiavon, J. Alloy. Compd., 739, 939-947 (2018).

22) M. Obaidullah, T. Furusawa, I. A. Siddiquey, N. M. Bahadur, M. Sato and N. Suzuki, Adv. Powder Technol., 29, 1804-1811 (2018).

23) Y. Z. Zheng, H. Ding, Y. Liu, X. Tao, G. Cao and J. F. Chen, J. Power Sources, 254, 153-160 (2014).

24) L. Yu, W. Shi, L. Lin, Y. Liu, R. Li, T. Peng and X. Li, Dalton T., 43, 8421-8430 (2014).

25) C. Zhao, D. Child, Y. Hu, N. Robertson, D. Gibson, S. C. Wang and Y. Q. Fu, RSC Adv., 4, 61153-61159 (2014). 